\title{
Diversity of resident plant communities could weaken their allelopathic resistance against alien and native invaders
}

\author{
Ling Yuan · Junmin Li $\cdot$ Mark van Kleunen $(\mathbb{D}$
}

Received: 19 July 2021 / Accepted: 26 October 2021 / Published online: 8 November 2021

(C) The Author(s) 2021

\begin{abstract}
Elton's classic diversity-invasibility hypothesis posits that diversity of resident communities increases resistance against invaders. We tested whether the diversity-invasibility relationsip might be mediated by allelopathic effects of the resident species. In a large germination experiment, we exposed seeds of six alien and six native test species to leachates of one, three, six or twelve species. The leachates tended to slightly delay germination, and almost all single-species leachates reduced the proportion of germinated seeds. Nevertheless, the overall effect of the plant leachate mixtures on the proportion of germinated seeds was not significant. This was because a higher diversity of the leachates increased the proportion of germinated seeds, particularly for native test species. Among the six alien test species, it was only the most invasive one that benefited from increased diversity of the leachates, just like the natives did. Overall, our findings suggest that
\end{abstract}

Supplementary Information The online version contains supplementary material available at https://doi.org/10.1007/ s10530-021-02667-5.

L. Yuan · J. Li · M. van Kleunen ( $ه)$

Zhejiang Provincial Key Laboratory of Plant Evolutionary

Ecology and Conservation, Taizhou University,

Taizhou 318000, China

e-mail: mark.vankleunen@uni-konstanz.de

M. van Kleunen

Ecology, Department of Biology, University of Konstanz, 78464 Konstanz, Germany allelopathy of diverse communities does not provide resistance but could actually facilitate the germination of invaders.

Keywords Allelochemicals · Biochemical recognition hypothesis $\cdot$ Exotic plants $\cdot$ Indigenous plants $\cdot$ Seedling emergence $\cdot$ Species richness

\section{Introduction}

With increasing globalization, more than 13,000 vascular plant species have established self-sustaining populations outside their native regions (van Kleunen et al. 2015; Pyšek et al. 2017). As a consequence, many local resident communities now consist of mixtures of native and naturalized alien plants. Some of the naturalized alien plants are considered invasive, as they spread rapidly (Richardson et al. 2000) and have negative ecological or socioeconomic impacts (Vilà and Hulme 2017; Schaffner et al. 2020). Given that the numbers of invasive alien plants will likely continue to increase (Seebens et al. 2020), it is important to identify mechanisms that underlie establishment of plants and invasibility of the resident communities (Sakai et al. 2001; van Kleunen et al. 2018).

Invasion success is, among others, determined by the interaction between the introduced plant and the 
resident community (Gallien and Carboni 2017; Theoharides and Dukes 2007). Invasive plants may outperform many resident plants due to superior competitive ability. The latter could be due to traits that allow the plants to quickly take up available resources, resulting in high intrinsic growth rates (Dawson et al. 2011; Zhang and van Kleunen 2019). It has also been suggested that the high competitive ability of some invasive plants could be achieved by suppression of germination and growth of neighboring plants by allelochemicals (Baker 1974; Callaway and Aschehoug 2000; Hickman et al. 2020). In support of this idea, Kalisz et al. (2021) showed that of the 524 invasive plant species in their database, at least half have known allelopathic effects. The role of allelopathy in invasion success is fundamental to the the novel weapons hypothesis (Callaway and Ridenour 2004), which posits that some alien plants have become invasive due to the production of chemical compounds that are toxic to the naïve native plants. Numerous studies find support for the novel weapons hypothesis (e.g. Ridenour and Callaway 2001; Abhilasha et al. 2008; Gómez-Aparicio and Canham 2008; Thorpe et al. 2009; Inderjit et al. 2011; Becerra et al. 2018), indicating that allelopathy might indeed play an important role in plant invasions.

Many resident plants are also likely to produce allelopathic compounds, and it could be that allelopathy of resident plants provides resistance against naïve invaders (Weidenhamer and Romeo 2005). In other words, it is likely that many alien plant species are also susceptible to the allelochemicals released by native species, as well as to the allelochemicals by other alien plants that are already widely naturalized and part of the resident community. The idea that resident communities produce allelochemicals that provide resistance against invaders was already proposed by Rabotnov (1982), and is now known as the homeland-security hypothesis (Cummings et al. 2012). Although this hypothesis has rarely been tested, evidence is accumulating that some native species have allelopathic effects on alien species (Cummings et al. 2012; Christina et al. 2015; Ning et al. 2016; Mignoni et al. 2018; Adomako et al. 2019; Yuan et al. 2021). However, it is not known how common this is, whether allelopathic effects of resident species on alien plants are stronger than those on native plants, and whether highly invasive aliens are less affected than non-invasive aliens.
The biotic resistance hypothesis, proposed by Elton (1958), suggests that resistance to invaders inceases with community diversity. Because of niche differentiation and complementarity, highly diverse communities should more fully capture available resources (Dostál 2011; Emery and Gross 2007; Ortega and Pearson 2005; van Ruijven et al. 2003), thereby reducing them to potential invaders. It is also possible that species-poor and species-rich communities differ in their allelopathic effects on newcomers. On the one hand, allelopathy may increase with diversity as there might be a higher chance that one of the species produces strong allelochemicals (i.e. a sampling effect) or that allelochemicals of different species act synergistically rather than additively. On the other hand, in more diverse communities the allelochemicals specific to each species may be diluted to levels at which they are not yet effective, resulting in a reduction of allelopathic effects with increasing diversity. The latter could be an explanation for the invasion paradox that many observational studies find positive instead of negative relationships between native and alien species richness (Fridley et al. 2007). To the best of our knowledge, these possibilities have not been rigorously tested yet.

To test if diversity of resident plant communities affects the strength of their allelopathic effects on invaders, and whether these effects depend on whether the invader is native or alien, we performed a large multi-species germination experiment. We produced aqueous leachates of 12 herbaceous resident species, including both natives and aliens, that frequently cooccur in fields in the Zhejiang province (China), and filled Petri-dishes with agar gel containing leachates from one, three, six and 12 species. In these Petridishes, we sowed seeds of six alien test species, varying in invasiveness status in China, and six native test species. Specifically, we addressed the following questions: (1) Do aqueous leachates of resident species exert allelopathic effects on germination of other species, and, if yes, do these effects depend (positively or negatively) on diversity of the resident plant community (i.e. on the number of species used to make the aqueous leachates)? (2) Do the alien test species suffer more from allelopathy than the native test species, and do effects of diversity of the leachates, if there are any, differ between native and alien species? (3) Among the alien species, do the ones 
that are more invasive in China suffer less from allelopathy?

\section{Material and methods}

Study species

For the production of the plant leachates, we selected 12 herbaceous plant species that co-occurred in a field in Taizhou, China (Table S1). We refer to those resident species as the allelopath species. Nine of the allelopaths are native and three of them are naturalized alien resident species. To avoid a possible bias by preferentially selecting resident species with known allelopathic effect, we did not consider a priori information on phytotoxic or allelopathic effects of the allelopath species. However, a posteriori literature searches showed that at least five of the species have documented allelopathic effects (Table S1). To test if the intensity of the allelopathic effect on a plant depends on its origin, we selected as test species six species that are native and six species that are alien to China. None of these 12 test species were included among our 12 allelopath species, and they were selected on the basis that they can occur in a similar range of habitats in China (Zhang and Ding 1993). In order to avoid a confounding of status with phylogeny, the native and alien species came from the same five families (Table S2). All six alien species are naturalized in more than 19 of the 34 Chinese regions (23 provinces, 5 autonomous regions, 4 municipalities, 2 special administrative regions) (Yan et al. 2019), and they vary in their degree of invasiveness in China, according to the invasiveness rankings of Yan et al. (2014). Seeds of the 12 allelopaths and the 12 test species were collected from fields in Taizhou (Zhejiang province, China) or obtained from commercial seed companies (Table S2).

\section{Experimental set-up and measurements}

On the $15^{\text {th }}$ of June 2020, to produce aqueous leachates of the 12 allelopath species, we sowed seeds of each of allelopath species in plastic trays $(1 \times \mathrm{w} \times \mathrm{h}=54 \times$ $28 \times 5 \mathrm{~cm}$ ) filled with a 1:1 (v:v) mixture of sand and vermiculite (both purchased from Xiaoxuan Horticulture, Hebei province, China). We placed the trays in a growth chamber (day-time temperature: $18-21^{\circ} \mathrm{C}$, night-time temperature: $16-20{ }^{\circ} \mathrm{C}$, day length: $14 \mathrm{~h}$, relative humidity: $60 \%$ ). We transplanted the seedlings, two weeks after emergence, into plastic pots (2 L) filled with a 1:1 (v:v) mixture of sand and vermiculite. We had one seedling per pot, and for each species, we had 10 pots, which we placed in a greenhouse (day-time temperature: $22-25{ }^{\circ} \mathrm{C}$, nighttime temperature: $18-21^{\circ} \mathrm{C}$, day length: $14 \mathrm{~h}$, relative humidity: 60\%). To ensure that we would have sufficient plant material for the production of leachates, we fertilized each pot once a week with $50 \mathrm{ml}$ of a liquid fertilizer for 14 weeks in total. The fertilizer (Woshibao ${ }^{\circledR}$ liquid fertilizer, Woshibao fertilizer sales Co., Ltd, Lu'an, China; N: 50 g/L, P: $30 \mathrm{~g} / \mathrm{L}, \mathrm{K}: 50 \mathrm{~g} / \mathrm{L}, \mathrm{Mg}: 1.8 \mathrm{~g} / \mathrm{L}, \mathrm{S}: 2.2 \mathrm{~g} / \mathrm{L}$, micronutrients: $0.2 \mathrm{~g} / \mathrm{L}$ ) was diluted 1:200 with distilled water. The plants were watered ad libitum twice a week.

To increase comparability to most other allelopathy studies (Zhang et al. 2021), we used plant leachates to test for allelopathic effects. On the 17th of September 2020 (i.e. after 14 weeks of growth), we harvested for each of the 12 allelopath species at least five plants (sometimes more when the plants were small). We harvested both the shoot and roots of each plant, and then cut each plant into pieces of $2 \mathrm{~cm}$. The root and shoot pieces of all plants per species were mixed, and we then took for each species a random sample of $300 \mathrm{~g}$ of plant material. The sampled plant material was then steeped in $900 \mathrm{ml}$ of distilled water for $24 \mathrm{~h}$ at room temperature. The resulting leachates were filtered in two steps. We first removed large plant debris using a layer of Whatman No. 1 filter paper, and after that we used a $0.8 \mu \mathrm{m}$ filter membrane $(25 \mathrm{~mm}$ in diameter) to remove fungal spores. We used a new filter membrane for each species. The filtrates were collected into separate autoclaved Falcon tubes, and stored at $-20{ }^{\circ} \mathrm{C}$ until use.

To test whether the pure aqueous leachates or their mixtures had allelopathic effects on germination of the seeds of the 12 test species, we did a large germination experiment at Taizhou University, China. A total of 1824 Petri-dishes (diameter: $6 \mathrm{~cm}$ ) were filled with agar substrate made with the aqueous plant leachates. From the twelve plant leachates, 37 different agarplant leachate-mixtures were produced at four levels of diversity: 12 single species leachates, 12 mixtures of three species, 12 mixtures of six species and one mixture of all 12 species. In addition, we had one control agar gel without any plant leachate. For the 
3-species and 6-species mixtures, the species were randomly selected, with the restriction that each species is part of an equal number of mixtures per diversity category (see Table S1).

For each resident allelopath species and each level of diversity, we mixed $300 \mathrm{ml}$ of pure leachate or $300 \mathrm{ml}$ of a leachate mixture into $600 \mathrm{ml}$ of liquid agar gel. The latter was made by mixing $12 \mathrm{~g}$ high-strength agar, $30 \mathrm{~g}$ sucrose and $3.225 \mathrm{~g}$ Murashige and Skoog culture medium in $1 \mathrm{~L}$ distilled water. We adjusted the $\mathrm{pH}$ of the agar solution to 6.0 with $\mathrm{NaOH}$ or HCL. We poured the agar solution into $1000 \mathrm{ml}$ Schott glass bottles, and then autoclaved it for $15 \mathrm{~min}$ at $120^{\circ} \mathrm{C}$ and a pressure of $100 \mathrm{kPa}$. Thereafter, hot agar medium was cooled down without solidifying by placing it for $10 \mathrm{~min}$ in a $40{ }^{\circ} \mathrm{C}$ water bath. We thawed the frozen plant leachates by placing them for 30 mintues in a heating cabinet at $40{ }^{\circ} \mathrm{C}$. We did not use a higher temperature to minimize the likelihood that some of the allelopathic substances would denature. We once more passed the leachates under sterile conditions through a $0.8 \mu \mathrm{m}$ filter membrane. We then used the 12 pure species leachates to create 12 threespecies, 12 six-species and one 12-species mixture (Fig. S1). So, in total there were 37 leachates. In addition, we made a water control of which the osmolality was adjusted with PEG (see below). For each of the leachates and the control, we mixed $300 \mathrm{ml}$ into $600 \mathrm{ml}$ of the liquid agar solution. We then poured for each of the 38 agar mixtures $10 \mathrm{ml}$ into 48 Petri-dishes (totalling 1824 Petri dishes), after which the agar mixture was allowed to cool down and solidify.

As osmolality might have an effect on the germination of the seeds (Inderjit and Nilsen 2003; Oduor et al. 2020), it was measured with an osmometer (Wescor 5600, Shanghai Pengqi Scientific Instrument Co., Ltd) for each of the 37 leachate mixtures three times, after the filtration step. Variation in the osmolality among leachate mixtures was not related to diversity (i.e. the number of species used to make the leachate mixtures; Fig. S1). For the control agar gel without plant leachates, we therefore adjusted the osmolality to the mean value calculated across all 37 plant leachates $(0.049 \mathrm{Osmol} / \mathrm{kg})$. To achieve this, the agar without plant leachate was mixed with a 8000-polyethylenglycol solution (8000-PEG; SigmaAldrich, Steinheim, Germany), which had a concentration of $0.091 \mathrm{~g} \mathrm{PEG} / \mathrm{ml}$. We used PEG, because it changes the osmolality, but cannot be absorbed by plant cells, due to its large molecular size, and is therefore unlikely to have phytotoxic effects (Michel and Kaufman 1973; Paparella et al. 2015).

In the period from the 6th to the 12th of December 2020, we sowed the seeds of the 12 test species. Before sowing the seeds, we sterilized them by putting them for $30 \mathrm{~s}$ in $75 \%$ alcohol, followed by five minutes in a $5 \%$ sodium hypochlorite solution. We then rinsed the seeds with distilled water. In each Petri-dish, we put 10 seeds of one of the 12 test species on the agar gel. For each combination of leachate type (37 plant leachates and 1 PEG control) and test species $(n=12)$, we had four replicates, resulting in 1824 Petri-dishes. Each Petri-dish was sealed with a strip of parafilm to prevent evaporative water loss. We then randomly assigned the Petri-dishes to positions within a growth chamber (day-time temperature: $21{ }^{\circ} \mathrm{C}$, night-time temperature: $16{ }^{\circ} \mathrm{C}$, day length: $15 \mathrm{~h}$, relative humidity: $60 \%$ ). Each day, we recorded how many seeds had germinated. About two weeks after the last seedling had emerged (on the $16^{\text {th }}$ of January 2021), the experiment was stopped. The collected data were used to calculate the proportion of germinated seeds and the days to first germination. We disgarded 60 Petri-dishes that were strongly infected with a fungus (PEG control: $\mathrm{n}=1$, diversity $1: \mathrm{n}=17$, diversity $3: \mathrm{n}=26$, diversity 6 : $\mathrm{n}=13$, diversity $12: \mathrm{n}=3$ ), resulting in a total of 1784 Petri-dishes with germination data.

\section{Statistical analysis}

We did all analyses and data visualization in $\mathrm{R}$ version 3.6.1 (R Development Core Team 2019). For the analysis of the proportion of germinated seeds (a binomial error distribution) and the number of days to first germination (a Poisson error distribution), we used generalized linear mixed models (GLMMs) as implemented in the glmer function of the lme4 package (Bates 2014).

The fixed terms in our models were 'Origin' (alien $v s$ native) of the test species, 'Leachate presence' (control vs plant leachates), 'Diversity' of allelopath species in the leachate' (1, 3, 6 or 12 species) and the interactions of these three factors. We initially also included osmolality of the leachate mixture as a covariable in the model, but as its effect was not significant, we removed it from the final model. We included Diversity as a continuous covariable when 
analyzing the effects of species number in the leachate mixture on germination parameters. Diversity was fitted after the effect of Leachate presence, so that it effectively only considered the Petri-dishes with plant leachates (i.e. not the control). We accounted for variation among test species by including species identiy as a random term. We initially also included plant family of the test species as a random term, but as the variance explained by family was very low and its inclusion resulted in singularity warnings, we removed it from the final models. Furthermore, as each of the 38 leachate mixtures (including the control) was used multiple times, we accounted for non-independence among Petri-dishes with the same leachate mixture by including leachate mixture as a random term. To test which of the allelopath species significantly affected the proportion of germinated seeds and the days to first germination, we also analysed the subset of data including only the control and the single-species leachates. In this analysis, allelopath species was included as a fixed term, and test species as a random term. In all GLMMs, we assessed the significance of the fixed terms with loglikelihood-ratio tests (Zuur et al. 2009), in which a model with the term of interest was compared to a model without that term. Log-likelihood ratios are approximately $\chi^{2}$-distributed (Zuur et al. 2009).

\section{Results}

Germination of alien and native test species

The proportion of seeds that germinated was significantly reduced by 11 of the 12 single-species aqueous plant leachates (Fig. 1a). Averaged over all allelopathdiversity levels, however, the proportion of germinated seeds was not significantly affected by the presence of aqueous plant leachates (Fig. 2a; $P=0.239$, Table 1). This is because the proportion of germinated seeds was positively affected by the diversity of the resident plants in the aqueous leachates (Fig. 2a; $P=0.022$, Table 1). The strength of the diversity effect on the proportion of germinated seeds differed significantly between the native and alien species (Fig. 2a; $P=0.005$, Table 1). For native species, the proportion of germinated seeds increased from a median of $34 \%$ at diversity- 1 to a median of $60 \%$ at diversity-12. For alien species, the proportion of germinated seeds was also lowest at diversity-1 (44\%), but was only slightly higher at the other diversity levels, with the highest germination at diversity-6 (53\%)(Fig. 2a).

The number of days until first germination was significantly increased by four of the 12 single-species aqueous plant leachates (Fig. 1b). As germination also tended to be more delayed with an increase in diversity of allelopath species (Fig. 2b; marginally non-significant effect $[P=0.062]$ in Table 1$)$, the overall effect of the presence of plant leachates on the number of days until first germination was significant (Fig. 2b; $P=0.020$, Table 1). The number of days to first germination of the alien and native species, however, did not differ across leachate-diversity levels (Fig. 2b; $P=0.362$, Table 1).

Germination of alien test species varying in invasiveness

Among the six alien test species, the proportion of germinated seeds varied considerably (Fig. 3a). The presence of aqueous plant leachates had no significant effects on the proportion of germinated seeds (Fig. 3a; $P=0.145$, Table 2). However, while germination of aliens in the lowest invasiveness categories tended to slightly decrease with diversity of the leachate, the opposite was true for the most invasive one (Fig. 3a; significant Invasiveness $\times$ Diversity interaction $[P=0.006]$ in Table 2). The presence of leachates tended to slighly speed up germination of the least invasive alien species, whereas it tended to slighly delay germination of the more invasive species (Fig. 3b, marginally non-significant Invasiveness $\times$ Leachate presence interaction $[P=0.062]$ in Table 2).

\section{Discussion}

We tested whether the frequently reported negative effect of diversity of resident communities on performance of invaders, both native and alien ones (Levine et al. 2004; Balvanera et al. 2006), might be mediated by allelopathy. We found that almost all single-species plant leachates reduced the proportion of germinated seeds and slightly delayed germination. Nevertheless, the average effect of the plant-leachate mixtures on the proportion of germinated seeds was not significant. 

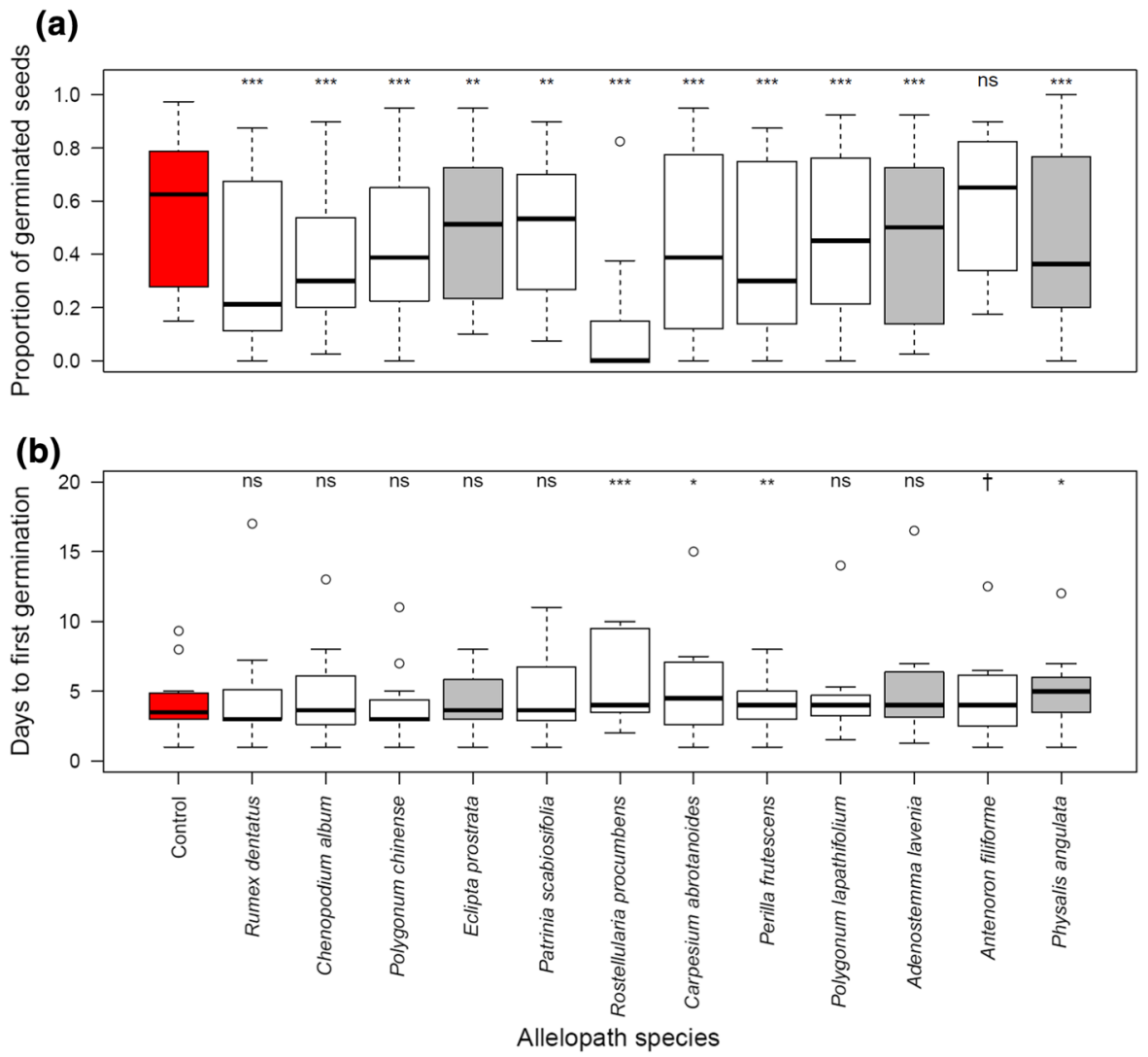

Fig. 1 Effects of the 12 single-species aqueous leachates on $\mathbf{a}$ the proportion of germinated seeds and $\mathbf{b}$ the number of days until first germination. The control treatment with PEG is in red, the native allelopath species are in white, and the alien allelopath species are in grey. Boxes show the interquartile

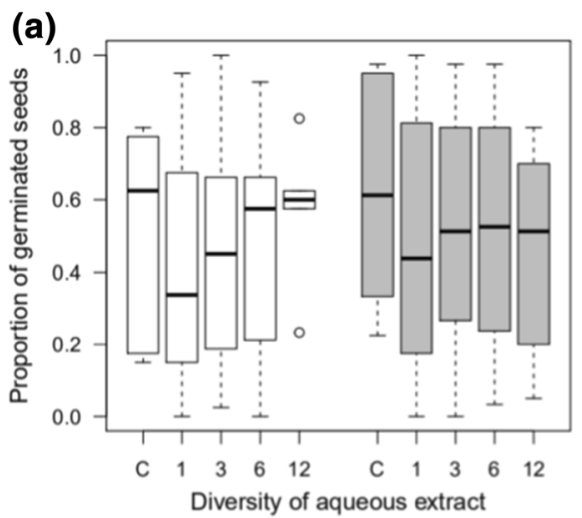

Fig. 2 Boxplots of a the proportion of germinated seeds and $\mathbf{b}$ the number of days to first germination for alien (grey filling of boxes) and native species (white filling), and treatments with different diversity of aqueous plant leachates. To account for the fact that observations on the same test species and the same aqueous leachate mixture are not independent, we first range around the median (thick horizontal line), whiskers extend to $1.5 \times$ the interquartile range, and circles indicate outliers. Significance levels for the deviations of allelopath leachates from the control treatment are indicated with $* * *: P \leq 0.001$, $* *: P \leq 0.01, *: P \leq 0.05, \dagger: 0.05<\mathrm{P} \leq 0.1, \mathrm{~ns}: P>0.1$

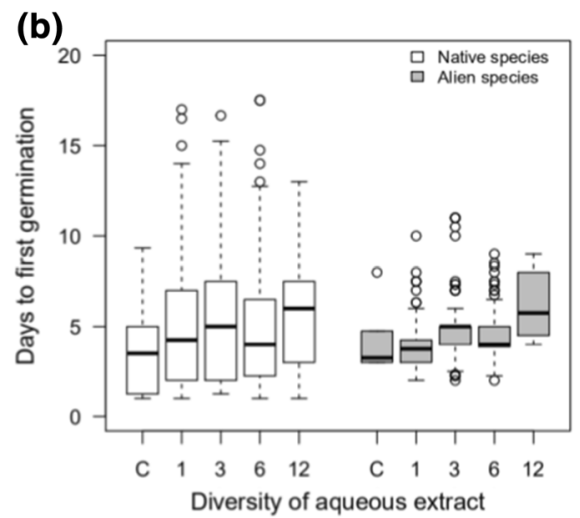

calculated the average values for each combination of a test species with an aqueous leachate mixture (or control treatment, C) and used these values to make the boxplots. Boxes show the interquartile range around the median (thick horizontal line), whiskers extend to $1.5 \times$ the interquartile range, and circles indicate outliers 
Table 1 Results of generalized linear mixed models testing for effects of origin of the test species (alien, native), leachate presence (control vs aqueous plant leachates), and diversity of plant species in the leachates (continuous covariate: $1,3,6,12$ species) on the proportion of germinated seeds (binomial distribution) and number of days to first germination (Poisson distribution)

\begin{tabular}{|c|c|c|c|c|c|}
\hline & \multirow[b]{2}{*}{ df } & \multicolumn{2}{|c|}{ Proportion of germinated seeds } & \multicolumn{2}{|c|}{ Days to first germination } \\
\hline & & $\chi^{2}$ & $P$ & $\chi^{2}$ & $P$ \\
\hline \multicolumn{6}{|l|}{ Fixed terms } \\
\hline Origin & 1 & 0.13 & 0.719 & 0.01 & 0.909 \\
\hline Leachate presence & 1 & 1.38 & 0.239 & 5.41 & $\mathbf{0 . 0 2 0}$ \\
\hline Diversity of leachate & 1 & 5.28 & 0.022 & 3.48 & 0.062 \\
\hline Origin $\times$ Leachate presence & 1 & 2.22 & 0.136 & 2.17 & 0.140 \\
\hline Origin $\times$ Diversity of leachate & 1 & 8.01 & 0.005 & 0.83 & 0.362 \\
\hline Random terms & & Standard deviation & & Standard deviation & \\
\hline Test species & & 1.279 & & 0.560 & \\
\hline Leachate mixture & & 0.409 & & 0.050 & \\
\hline
\end{tabular}

For the proportion of germinated seeds, $n=1764$, and for days to germination, $n=1568$. $P$-values $<0.05$ are highlighted in bold, and $P$-values $<0.1$ (and $>0.05$ ) are highlighted in italics
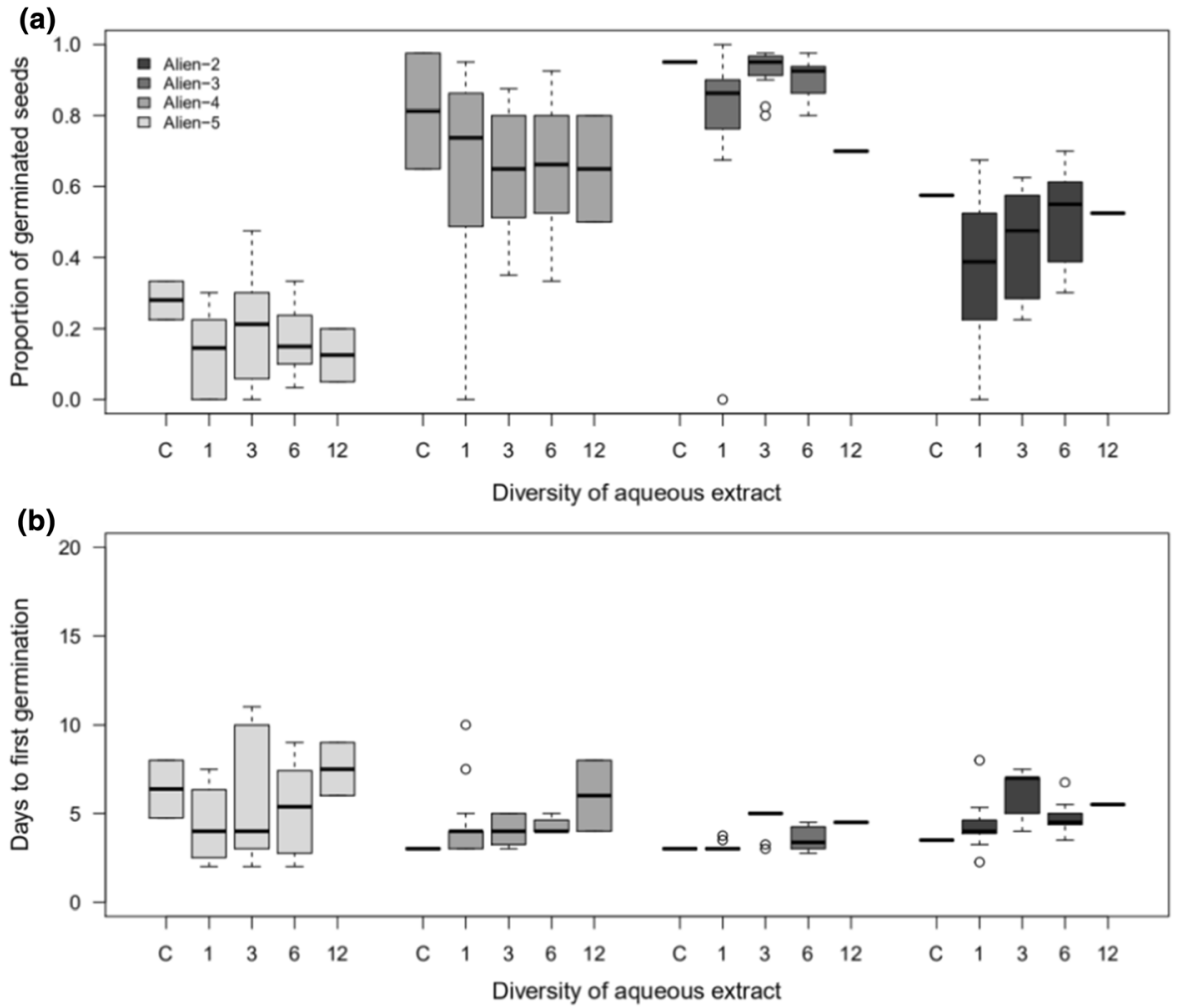

Fig. 3 Boxplots of a the proportion of germinated seeds and b the number of days to first germination for alien invasive species of different invasiveness degree, and treatments with different diversity of aqueous plant leachates. To account for the fact that observations on the same test species and the same aqueous leachate mixture are not independent, we first calculated the average values for each combination of a test species with an aqueous leachate mixture (or control treatment, C) and used these values to make the boxplots. Boxes show the interquartile range around the median (thick horizontal line), whiskers extend to $1.5 \times$ the interquartile range, and circles indicate outliers 
Table 2 Results of generalized linear mixed models testing for effects of the degree of invasiveness of the alien species (a continuous variable), leachate presence (control vs aqueous plant leachates), and diversity of plant species in the leachates (continuous covariate: 1, 3, 6, 12 species) on the proportion of germinated seeds (binomial distribution) and number of days to first germination (Poisson distribution) for the subset of six alien species

\begin{tabular}{|c|c|c|c|c|c|}
\hline & \multirow[b]{2}{*}{ df } & \multicolumn{2}{|c|}{ Proportion of germinated seeds } & \multicolumn{2}{|c|}{ Days to first germination } \\
\hline & & $\chi^{2}$ & $P$ & $\chi^{2}$ & $P$ \\
\hline \multicolumn{6}{|l|}{ Fixed terms } \\
\hline Invasiveness & 1 & 2.01 & 0.156 & 0.08 & 0.790 \\
\hline Leachate presence & 1 & 2.12 & 0.145 & 0.61 & 0.433 \\
\hline Diversity of leachate & 1 & 1.96 & 0.161 & 1.79 & 0.181 \\
\hline Invasiveness $\times$ Leachate presence & 1 & 0.04 & 0.836 & 3.49 & 0.062 \\
\hline Invasiveness $\times$ Diversity of leachate & 1 & 7.42 & 0.006 & 0.46 & 0.497 \\
\hline Random terms & & Standard deviation & & Standard deviation & \\
\hline Test species & & 1.235 & & 0.285 & \\
\hline Leachate mixture & & 0.444 & & 0.116 & \\
\hline
\end{tabular}

For the proportion of germinated seeds, $n=868$, and for days to germination, $n=774$. $P$-values $<0.05$ are highlighted in bold, and $P$-values $<0.1$ (and $>0.05)$ are highlighted in italics

This was because a higher diversity of the leachates increased the proportion of germinated seeds, particularly for native test species. Among the six alien test species, however, it was only the most invasive one, Trifolium repens, that benefited from increased diversity of the leachates, just like the natives did. Overall, our findings suggest that allelopathy of diverse communities does not provide resistance but could actually facilitate the germination and thus establishment of new alien and native species (i.e. diversity begets diversity; Palmer and Maurer 1997).

The classic diversity-invasibility hypothesis posits that species-rich communities should be more resistant to invasions than species-poor communities (Elton 1958; Levine and D'Antonio 1999; Naeem et al. 2000; Fridley et al. 2007). Observational studies, however, usually find positive correlations between native and alien species richness (Stohlgren et al. 2003; Peng et al. 2019). This likely reflects the greater inclusion of factors that covary with native and nonnative diversity as spatial scale increases (e.g., soil heterogeneity, disturbance; Fridley et al. 2007). Our findings of positive effects of the number of species used to make aqueous plant leachates on germination suggest that allelopathy could also contribute to positive diversity-invasibility relationships. On the other hand, most other experimental studies that manipulated the number of species in a native community found negative diversity-invasibility relationships (summarized in the meta-analysis by Levine et al. 2004). So, our findings appear to be at odds with those of other experimental studies. However, Feng et al. (2019) found that while diversity had negative effects on later life stages of invaders, it tended to have a positive effect on seed germination. Coupling their findings with ours most likely reflect that the frequently invoked mechanism behind negative diversity-invasibility relationships-resource depletion by diverse communities due to niche complementarity (Dostál 2011; Emery and Gross 2007; Fargione and Tilman 2005; Grace et al. 2017) or the sampling effect (Petruzzella et al. 2018; Qin et al. 2013; Wardle 2001) — does not act yet at the germination stage. At the later stages, when the plants started growing and have to compete with the resident community, the negative effects of species diversity on establishment and performance of new species may appear.

Although diversity may not increase biotic resistance at the germination stage for the reason mentioned above, this does not explain why we found a positive effect (instead of no effect) of diversity on the proportion of germinated seeds. We had expected that with increasing diversity the chance that the mixture would contain a strongly allelopathic species would increase or that allelochemicals of different species would act synergistically. The positive effect 
obviously cannot be explained by these mechanisms. A possible explanation for our findings could be that some of the allelopath species facilitate germination, and that diverse mixtures are more likely to include some of those facilitators or "diversity promoters" (Palmer and Maurer 1997). However, none of the 12 allelopath species used had positive effects on germination when used as a single-species plant leachate (Fig. 1). A more likely explanation therefore would be the dilution mechanism. If a species produces allelochemicals that act in a dose-response manner (Xia et al. 2016), these allelochemicals may have been diluted in the mixtures to concentrations at which they are ineffective. Moreover, at low concentrations, allelochemicals may even act as chemical facilitators for some plant species (Weir et al. 2006; Prithiviraj et al. 2007). For example, Prithiviraj et al. (2007) found that low concentrations of the allelochemical flavonol ( \pm )-catechin, which presumably plays a major role in the invasion success of Centaurea maculosa in North America (Bais et al. 2003; but see Perry et al. 2007), resulted in improved growth and survival of Arabidopsis thaliana when applied at very low concentrations. Indeed, many toxins can have entirely different effects on target organisms at low than at high concentrations (Calabrese and Baldwin 2003).

Another potential explanation for our findings is provided by the biochemical recognition hypothesis (Renne et al. 2004, 2014). This hypothesis posits that metabolites produced by resident plants might be used by seeds to eavesdrop on which species are present. If there is a strong competitor among the resident species that would result in mortality or poor performance of the seedling, metabolites produced by the resident species might be used as a chemical cue to defer germination until better establishment conditions occur (i.e. the seed would remain or go dormant). This biochemical eavesdropping mechanism will only work if species have evolved to recognize each other's metabolites, and should thus be more likely to function between sympatric species than between allopatric species (Renne et al. 2004, 2014). In other words, it should work better between two coevolved native species than between an alien and a native species. Several studies report support for this hypothesis (Renne et al. 2004, 2014; Yannelli et al. 2020). As in multi-species communities the chemical signatures of each resident is diluted, one would expect the strongest reduction of germination when using single-species leachates, and particularly for native test species. The significant Origin $\times$ Diversity interaction for the proportion of germinated seeds indicates that this was indeed the case in our study (Fig. 2). To test whether biochemical recognition and induced dormancy could explain reduced germination in the presence of sympatric species, future studies should test whether the seeds that did not germinate are still viable.

To gain more insights into the possible mechanisms underlying the observed diversity effects, we did some additional analyses on the proportion of germinated seeds following the hierarchical diversity-interaction modeling approach of Kirwan et al. (2009; see Appendix 1). This approach compares a null model, a model with species identity effects only and several models that also include interactions between species to infer the contributions of species identities and their interactions to diversity effects on germination of the test species (Fig. S2). For the proportion of germinated seeds, this additional analysis showed that the model with the lowest AIC (i.e. the best model) was the one that included separate pairwise interactions between the allelopath species as well as the interaction with whether or not the test species is alien or native (Table S3). This means that the effect of a mixture on germination is not solely due to identity effects of its component species, but also due to interaction effects that differ among each combination of species, and that these identity and interaction effects also depend on the origin of the test species. The latter could be the reason why the effect of diversity of leachate on germination is dependent on the origin of the test species. The separate interaction effects that we found are likely to be common. For example, Law and Morton (1996) also showed that certain combinations of species better resist invasion than others of equal diversity. In other words, our finding indicates that it is very difficult to predict the effects of a certain combination of species on the proportion of germinated seeds.

We found neither evidence that the alien test species suffered more from allelopathy than the native test species nor that among the alien species, the ones that are more invasive suffered less from allelopathy. On the contrary, the alien test species tended to reduce their germination to a lesser extent in response to the single-species leachates than the native test species 
did. This is in line with the predictions of the biochemical recognition hypothesis (Renne et al. 2004, 2014). Furthermore, our findings suggest that the native test species were not more adapted to allelochemicals of the resident species than the aliens were, and that the aliens that have become highly invasive are not immune against allelochemicals of resident species. The lack of support for our hypotheses might partly be due to the fact that three of the 12 resident species we used for making plant leachates were also alien. This was done to reflect that many of our current novel ecosystems consist of mixtures of native and naturalized alien plants (Richardson and Gaertner 2013). Inspection of the effects of the singlespecies plant leachates on germination, however, did not reveal any clear differences in the effects of native and alien allelopaths (Fig. 1). A recent meta-analysis found that native plants suffered more from leachates of naturalised alien plants than from leachates of other native plants (Zhang et al. 2021). However, in a recent study on reciprocal allelopathy, researchers found that alien-native interactions did not consistently deviate from native-native interactions or alien-alien interactions (Yuan et al. 2021). Therefore, we think that it is unlikely that the use of alien allelopaths is responsible for the absence of differences in susceptibility to allelopathy of the alien and native test species.

Research on allelopathy is challenging, and a wide variety of experimental approaches have been used to test for allelopathic interactions (Zhang et al. 2021). However, all of them have their methodological limitations. Like most other studies, we used leachates of freshly cut material collected on plants grown in standard substrate under optimal greenhouse conditions. We can therefore not exclude the possibility that the chemical composition of the plants differ from those in natural environments. Moreover, some metabolites might have leached from the cut plant material that would never leach from intact plants, or not at such high concentrations. Furthermore, in nature, soil properties and the presence of microbes might also affect the phytotoxic effect of the leachates (Inderjit and van der Putten 2010). These limitations should be kept in mind when interpreting the results of studies on allelopathy. Nevertheless, experiments, like ours, done under standardized conditions provide first insights into the potential ecological and evolutionary importance of allelopathy and biochemical recognition. The next step should be to test their importance in nature, when suitable approaches become available.

\section{Conclusion}

Although aqueous leachates of 11 of the 12 resident species in our study had negative effects on germination of the test species, these effects disappeared when we mixed the leachates of the different species. Most likely this is because the specific allelochemicals of the different species are diluted in the mixtures. In nature, it is also likely that the concentrations of the allelochemicals produced by each species will be lower in highly diverse communities than in monocultures. If this is indeed the case, this means that the frequently reported negative diversity-invasibility relationship cannot be explained by allelopathy.

Acknowledgements This work was supported by the Research Foundation for Advanced Talents of Taizhou University(No. 0104010008-98693).

Author contributions $\mathrm{MvK}$ and JL came up with the idea. YL and $\mathrm{MvK}$ designed the experiment. YL performed the experiment. MvK and YL analysed the data. YL and MvK wrote the paper with contributions of JL.

Funding Open Access funding enabled and organized by Projekt DEAL. This work was supported by the Research Foundation for Advanced Talents in Taizhou University (Grant No. 0104010008).

Data availability Upon acceptance of the manuscript, the data will be made available through Figshare.

\section{Declarations}

Conflict of interest The authors have no conflicts of interest to declare that are relevant to the content of this article.

Open Access This article is licensed under a Creative Commons Attribution 4.0 International License, which permits use, sharing, adaptation, distribution and reproduction in any medium or format, as long as you give appropriate credit to the original author(s) and the source, provide a link to the Creative Commons licence, and indicate if changes were made. The images or other third party material in this article are included in the article's Creative Commons licence, unless indicated otherwise in a credit line to the material. If material is not included in the article's Creative Commons licence and your intended use is not permitted by statutory regulation or exceeds the permitted use, you will need to obtain permission directly 
from the copyright holder. To view a copy of this licence, visit http://creativecommons.org/licenses/by/4.0/.

\section{References}

Abhilasha D, Quintana N, Vivanco J, Joshi J (2008) Do allelopathic compounds in invasive Solidago canadensis s.l. restrain the native European flora? J Ecol 96:993-1001

Adomako MO, Ning L, Tang M, Du D, van Kleunen M, Yu F (2019) Diversity and density mediated allelopathic effects of resident plant communities on invasion by an exotic plant. Plant Soil 440:581-592

Bais HP, Vepachedu R, Gilroy S, Callaway RM, Vivanco JM (2003) Allelopathy and exotic plant invasion: from molecules and genes to species interactions. Science 301:1377-1380

Baker HG (1974) The evolution of weeds. Annu Rev Ecol Evol S 5:1-24

Balvanera P, Pfisterer AB, Buchmann N, He J, Nakashizuka T, Raffaelli D, Schmid B (2006) Quantifying the evidence for biodiversity effects on ecosystem functioning and services. Ecol Lett 9:1146-1156

Bates D, Mächler M, Bolker BM, Sc W (2014) Package lme4: linear mixed-effects models using Eigen and S4. R Package Version 1:1-7

Becerra P, Catford J, Inderjit LM, Andonian K, Aschehoug E, Montesinos D, Callaway R (2018) Inhibitory effects of Eucalyptus globulus on understorey plant growth and species richness are greater in non-native regions. Global Ecol Biogeogr 27:68-76

Calabrese EJ, Baldwin LA (2003) Hormesis: the dose-response revolution. Annu Rev Pharmacol Toxicol 43:175-197

Callaway RM, Aschehoug ET (2000) Invasive plants versus their new and old neighbors: a mechanism for exotic invasion. Science 290:521-523

Callaway RM, Ridenour W (2004) Novel weapons: Invasive success and the evolution of increased competitive ability. Front Ecol Environ 2:436-443

Christina M, Rouifed S, Puijalon S, Vallier F, Meiffren G, Bellvert F, Piola F (2015) Allelopathic effect of a native species on a major plant invader in Europe. Sci Nature 102:12

Cummings JA, Parker IM, Gilbert GS (2012) Allelopathy: a tool for weed management in forest restoration. Plant Ecol 213:1975-1989

Dawson W, Fischer M, van Kleunen M (2011) The maximum relative growth rate of common UK plant species is positively associated with their global invasiveness. Global Ecol Biogeogr 20:299-306

Dostál P (2011) Plant Competitive Interactions and Invasiveness: Searching for the effects of phylogenetic relatedness and origin on competition intensity. Am Nat 177:655-667

Elton C (1958) The ecology of invasions. Methuen

Emery SM, Gross KL (2007) Dominant species identity, not community evenness, regulates invasion in experimental grassland plant communities. Ecology 88:954-964
Fargione J, Tilman D (2005) Diversity decreases invasion via both sampling and complementarity effects. Ecol Lett 8:604-611

Feng Y, Fouqueray T, van Kleunen M (2019) Linking Darwin's naturalisation hypothesis and Elton's diversity-invasibility hypothesis in experimental grassland communities. J Ecol 107:794-805

Fridley JD, Stachowicz JJ, Naeem S, Sax DF, Seabloom EW, Smith MD, Stohlgren TJ, Tilman D, Von Holle B (2007) The invasion paradox: reconciling pattern and process in species invasions. Ecology 88:3-17

Gallien L, Carboni M (2017) The community ecology of invasive species: Where are we and what's next? Ecography 40:335-352

Gómez-Aparicio L, Canham LC (2008) Neighbourhood analyses of the allelopathic effects of Blackwell Publishing Ltd the invasive tree Ailanthus altissima in temperate forests. J Ecol 96:447-458

Grace JB, Harrison S, Cornell H (2017) Is biotic resistance enhanced by natural variation in diversity? Oikos 126:1484-1492

Hickman DT, Rasmussen A, Ritz K, Birkett MA, Neve P (2020) Allelochemicals as multi-kingdom plant defence compounds: towards an integraged approach. Pest Manag Sci 77:1121-1131

Inderjit EH, Crocoll C, Bajpai D, Kaur R, Feng Y, Silva C, Carreón JT, Valiente-Banuet A, Gershenzon J, Callaway R (2011) Volatile chemicals from leaf litter are associated with invasiveness of a neotropical weed in Asia. Ecology 92:316-324

Inderjit, and Nilsen ET (2003) Bioassays and field studies for allelopathy in terrestrial plants: progress and problems. Crit Rev Plant Sci 22: 221-238.

Inderjit, and van der Putten WH (2010) Impacts of soil microbial communities on exotic plant invasions. Trends Ecol Evol 25: 512-519

Kalisz S, Kivlin SN, Bialic-Murphy L (2021) Allelopathy is pervasive in invasive plants. Biol Invasions 23:367-371

Kirwan L, Connolly J, Finn JA, Brophy C, Lüscher A, Nyfeler D, Sebastia MT (2009) Diversity-interaction modeling: estimating contributions of species identities and interactions to ecosystem function. Ecology 90:2032-2038

Law M, Law R, Morton RD (1996) Permanence and the assembly of ecological communities. Ecology 77:762-775

Levine JM, D'Antonio CM (1999) Elton revisited: a review of evidence linking diversity and invasibility. Oikos 87:15-26

Levine JM, Adler PB, Yelenik SG (2004) A meta-analysis of biotic resistance to exotic plant invasions. Ecol Lett 7:975-989

Michel BE, Kaufman MR (1973) The osmotic potential of polyethylene glycol 6000. Physiology 51:914-916

Mignoni D, Simões K, Braga M (2018) Potential allelopathic effects of the tropical legume Sesbania virgata on the alien Leucaena leucocephala related to seed carbohydrate metabolism. Biol Invasions 20:165-180

Naeem S, Knops JMH, Tilman D, Howe KM, Kennedy T, Gale S (2000) Plant diversity increases resistance to invasion in the absence of covarying extrinsic factors. Oikos 91:97-108

Ning L, Yu F, van Kleunen M (2016) Allelopathy of a native grassland community as a potential mechanism of 
resistance against invasion by introduced plants. Biol Invasions 18:3481-3493

Oduor A, van Kleunen M, Stift M (2020) Allelopathic effects of Brassica nigra in both its native and invasive ranges do not support the novel-weapons hypothesis. Am J Bot 107:1106-1113

Ortega Y, Pearson D (2005) Weak vs. strong invaders of natural plant communities: Assessing invasibility and impact. Ecol Appl 15:651-661

Palmer MW, Maurer T (1997) Does diversity beget diversity? A case study of crops and weeds. J Veg Sci 8:235-240

Paparella S, Araújo SS, Rossi G, Wijayasinghe M, Carbonera D, Balestrazzi A (2015) Seed priming: state of the art and new perspectives. Plant Cell Rep 34:1281-1293

Peng S, Kinlock NL, Gurevitch J, Peng S (2019) Correlation of native and exotic species richness: a global meta-analysis finds no invasion paradox across scales. Ecology 100:e02552

Perry LG, Thelen GC, Ridenour WM, Callaway RM, Paschke MW, Vivanco JM (2007) Concentrations of the allelochemical $( \pm)$-catechin in Centaurea maculosa soils. J Chem Ecol 33:2337-2344

Petruzzella A, Manschot J, van Leeuwen CHA, Grutters BMC, Bakker ES (2018) Mechanisms of invasion resistance of aquatic plant communities. Front Plant Sci 9:134

Prithiviraj B, Perry LG, Badri DV, Vivanco JM (2007) Chemical facilitation and induced pathogen resistance mediated by a root-secreted phytotoxin. New Phytol 173:852-860

Pyšek P, Pergl J, Essl F, Lenzner B, Dawson W, Kreft H, Weigelt P, Winter M, Kartesz J, Nishino M, Antonova L, Barcelona J, Cabezas F, Cárdenas D, Cárdenas-Toro J, Castaño N, Chacón-Madrigal E, Chatelain C, Dullinger S, van Kleunen M (2017) Naturalized alien flora of the world: Species diversity, taxonomic and phylogenetic patterns, geographic distribution and global hotspots of plant invasion. Preslia 89:203-274

Qin R, Zheng Y, Valiente-Banuet A, Callaway RM, Barclay G, Pereyra C, Feng Y (2013) The evolution of increased competitive ability, innate competitive advantages, and novel biochemical weapons act in concert for a tropical invader. New Phytol 197:979-998

Rabotnov TA (1982) Importance of the evolutionary approach to the study of allelopathy. Ekologia 3:5-8

Renne IJ, Rios BG, Fehmi JS, Tracy BF (2004) Low allelopathic potential of an invasive forage grass on native grassland plants: a cause for encouragement? Basic Appl Ecol 5:261-269

Renne IJ, Sinn BT, Shook GW, Sedlacko DM, Dull JR, Villarreal D, Hierro JL (2014) Eavesdropping in plants: delayed germination via biochemical recognition. J Ecol 102:86-94

Richardson DM, Pyšek P, Rejmánek M, Barbour MG, West FD, Panetta CJ (2000) Naturalization and invasion of alien plants: concepts and definitions. Divers Distrib 6:93-107

Richardson DM, and Gaertner M (2013) Plant invasion as builders and shapers of novel ecosystems. In: novel ecosystems. In Richard JH, Eric SH, and Carol MH (Eds), Intervening in the new ecological world order (1st ed). Wiley
Ridenour WM, Callaway RM (2001) The relative importance of allelopathy in interference: the effects of an invasive weed on a native bunchgrass. Oecologia 126:444-450

Sakai AK, Allendorf FW, Holt JS, Lodge DM, Molofsky J, Baughman KAS, Cabin RJ, Cohen JE, Ellstrand NC, McCauley DE, O'Neil P, Parker IM, Thompson JN, Weller SG (2001) The population biology of invasive species. Annu Rev Ecol Syst 32:305-332

Schaffner U, Steinbach S, Sun Y, Skjøth C, De Weger L, Lommen S, Augustinus BA, Bonini M, Karrer G, Šikoparija B, Thibaudon M, Müller-Schärer H (2020) Biological weed control to relieve millions from Ambrosia allergies in Europe. Nat Commun 11:1745

Seebens H, Bacher S, Blackburn T, Capinha C, Dawson W, Dullinger S, Lenzner B, Andrew LA, Pattison Z, Pergl J, Pyšek P, Winter M, Essl F (2020) Projecting the continental accumulation of alien species through to 2050 . Global Change Biol 27:16

Stohlgren TJ, Barnett DT, Katesz JT (2003) The rich get richer: patterns of plant invasions in the United States. Front Ecol Environ 1:11-14

Theoharides KA, Dukes JS (2007) Plant invasion across space and time: factors affecting nonindigenous species success during four stages of invasion. New Phytol 176:256-273

Thorpe A, Thelen G, Diaconu A, Callaway R (2009) Root exudate is allelopathic in invaded community but not in native community: Field evidence for the novel weapons hypothesis. J Ecol 97:641-645

van Kleunen M, Dawson W, Maurel N (2015) Characteristics of successful alien plants. Mol Ecol 24:1954-1968

van Kleunen M, Bossdorf O, Dawson W (2018) The ecology and evolution of alien plants. Annu Rev Ecol Evol Syst 49:25-47

van Ruijven De, Deyn GB, Berendse F (2003) Diversity reduces invasibility in experimental plant communities: the role of plant species. Ecol Lett 6:910-918

Vilà M, Hulme PE (2017) Impact of biological invasions on ecosystem services. Springer, Berlin

Wardle DA (2001) Experimental demonstration that plant diversity reduces invasibility- evidence of a biological mechanism or a consequence of sampling effect? Oikos 95:161-170

Weidenhamer JD, and Romeo JT (2005) Allelopathy as a mechanism for resisting invasion: the case of Polygonella myriophylla. In: Inderjit, (Eds.) Invasive Plants: Ecological and agricultural aspects. Birkhäuser Basel.

Weir TL, Bais HP, Stull VJ, Callaway RM, Thelen GC, Ridenour WM, Bhamidi S, Stermitz FR, Vivanco JM (2006) Oxalate contributes to the resistance of Gaillardia grandiflora and Lupinus sericeas to a phytotoxin produced by Centaurea maculosa. Planta 223:785-795

Xia Z, Kong C, Chen L, Wang P, Wang S (2016) A broadleaf species enhances an autotoxic conifers growth through belowground chemical interactions. Ecology 97:2283-2292

Yan X, Liu Q, Shou H (2014) The categorization and analysis on the geographic distribution patterns of Chinese alien invasive plants. Biodiversity Sci 22:667-676

Yan X, Wang Z, and Ma J (2019) The checklist of the naturalized plants in China. Shanghai scientific and technical publishers. 
Yannelli FA, Novoa A, Lorenzo P, Rodríguez J, Le Roux JJ (2020) No evidence for novel weapons: biochemical recognition modulates early ontogenetic processes in native species and invasive acacias. Biol Invasions 22:549-562

Yuan L, Li J, Yu F, Oduor A, van Kleunen M (2021) Allelopathic and competitive interactions between native and alien plants. Biol Invasions 23:3077-3090

Zhang Z, Liu Y, Ling Y, Weber E, van Kleunen M (2021) Effect of allelopathy on plant performance: a meta-analysis. Ecol Lett 24:348-362
Zhang Z, van Kleunen M (2019) Common alien plants are more competitive than rare natives but not than common natives. Ecol Lett 22:1378-1386

Zhang S, and Ding B (1993) Zhejiang Flora. Zhejiang Science and Technology Publishing House.

Zuur A, Ieno EN, Walker N, Saveliev AA, Smith GM (2009) Mixed effects models and extensions in ecology with R. Springer, Berlin

Publisher's Note Springer Nature remains neutral with regard to jurisdictional claims in published maps and institutional affiliations. 